\title{
The central part of the Filchner-Ronne Ice Shelf, Antarctica: internal structures revealed by $40 \mathrm{MHz}$ monopulse RES
}

\author{
N. BLINDOW \\ Institut für Geophrsik, Forschungsstelle für physikalische Glaziologie der Westfälischen Wilhelms-Universität Münster. \\ D-48149 Münster, German?
}

\begin{abstract}
ABSTR AC'T. About $1200 \mathrm{~km}$ of surface-based radio-echo sounding (RES) profiles were measured during the German Antarctic field season 1989-90 on the Filchner. Ronne Ice Shelf (FRIS), Antarctica, with a $40 \mathrm{MHz}$ monopulse sounder developed in Münster. In the area investigated, downstrcam of Doake Ice Rumples and Henry Ice Rise, a basal layer of marine ice up to $400 \mathrm{~m}$ thick was found below the meteoric ice. which is less than $100 \mathrm{~m}$ thick in some places. High absorption losses and low bottom reflectivity of the basal layer prevented sounding of the total ice thickness, except for areas near the ice edge with strong melting.

From common mid-point (CMP) measurements, the velocities of electromagnetic wases in the ice shelf were determined, to obtain precise depths from travel times for airborne and surface-based soundings.

The continuous profiling yielded the total ice thickness in the northern part and a variety of internal structures, including layers in the meteoric and the marine ice, remnants of crevasses, varying reflections of the meteoric-marine interface reflection (MMR). From these data, it is shown that the most-disturbed MMR signatures originate at grounding zoncs at Doake Ice Rumples and at both sides of Henry Ice Risc. The status of the meteoric ice bottom is preserved by the formation of marine ice. Hence, structures remain widely unchanged over $400 \mathrm{~km}$ of flow. Intcrnal features that can be correlated on parallel profiles perpendicular to the flow provide an independent means for the construction of flowlines. Even in areas with a smooth MMR, reflection amplitudes show variations by a factor of 2 . Their spatial frequency is maximal on profiles prependicular to the flow direction. A possible cxplanation for the amplitude variations is the varying salinity of the top of the marine ice.
\end{abstract}

\section{INTRODUCTION}

The central part of the Filchner-Ronne Ice Shelf (FRIS) consists of an upper layer of fresh ice from snow precipitation (metcoric icc) and a basal layer of icc formed by freezing of ice from the sea below the ice shelf imarine ice). The latter was found in 1984 during aerogeophysical measurements by Thyssen $(1986,1988)$. The Münster group conlirmed the predicted thickness of the marine ice by hot-water drilling in 1986 Lngelhardt and Detcrmann, 1987). From airborne measurements, we found that the area with a basal layer of marine ice extends to about $110000 \mathrm{~km}^{2}$, with a maximum marineice thickness of more than $400 \mathrm{~m}$ (Thyssen and others, in press). Core drillings (Oerter and others, 1992a) confirmed the marine origin of the basal layer. Hotwater drilling with borehole instrumentation (Grosfeld, 1993 gave the temperature distribution to the bottom and also in the seat. Measurements of the dielectric properties of the marine ice on core samples, recovered by Gross and Blindow (first results in Blindow (1990)), showed that the propagation velocity is the same as in fresh-water ice. The absorption in marine ice at $-28^{\circ} \mathrm{C}$ is
$18 \mathrm{~dB} 100 \mathrm{~m}^{2}$ at the top of the layer and $14 \mathrm{~dB} 100 \mathrm{~m}^{1}$ $50 \mathrm{~m}$ below, whereas the absorption in the meteoric ice is $1.8 \mathrm{~dB} 100 \mathrm{~m}^{-1} . \Delta \mathrm{t}-5^{\circ} \mathrm{C}$, the absorption in the marine ice increases to the range of $2530 \mathrm{~dB} 100 \mathrm{~m}^{1}$.

For a closer look at structural features in this unique regime, $40 \mathrm{MHz}$ monopulsc radio-echo soundings with high resolution were performed on an oversnow traverse during the German Filchner Expedition 1989 90 (pre-ceded by minor investigations in 198384 and 1985-86). The location of the profiles is shown in Figure 1. The total length of measured profiles is $1200 \mathrm{~km}$ and some of them are closely parallel and mcasured with different $\mathrm{RF}$ sct-ups. The Münster monopulse sounder has been developed for the profiling of glaciological and geological structures, offering a good compromise between resolution, range and processing of measurements. For the data processing, techniques adopted from reflection seismics are used. From the results of the measurements, three major points have been chosen for this paper: the detcrmination of velocity-travel-time functions on the FRIS, the structural interpretation of profiles and the investigation of reflection amplitudes. 


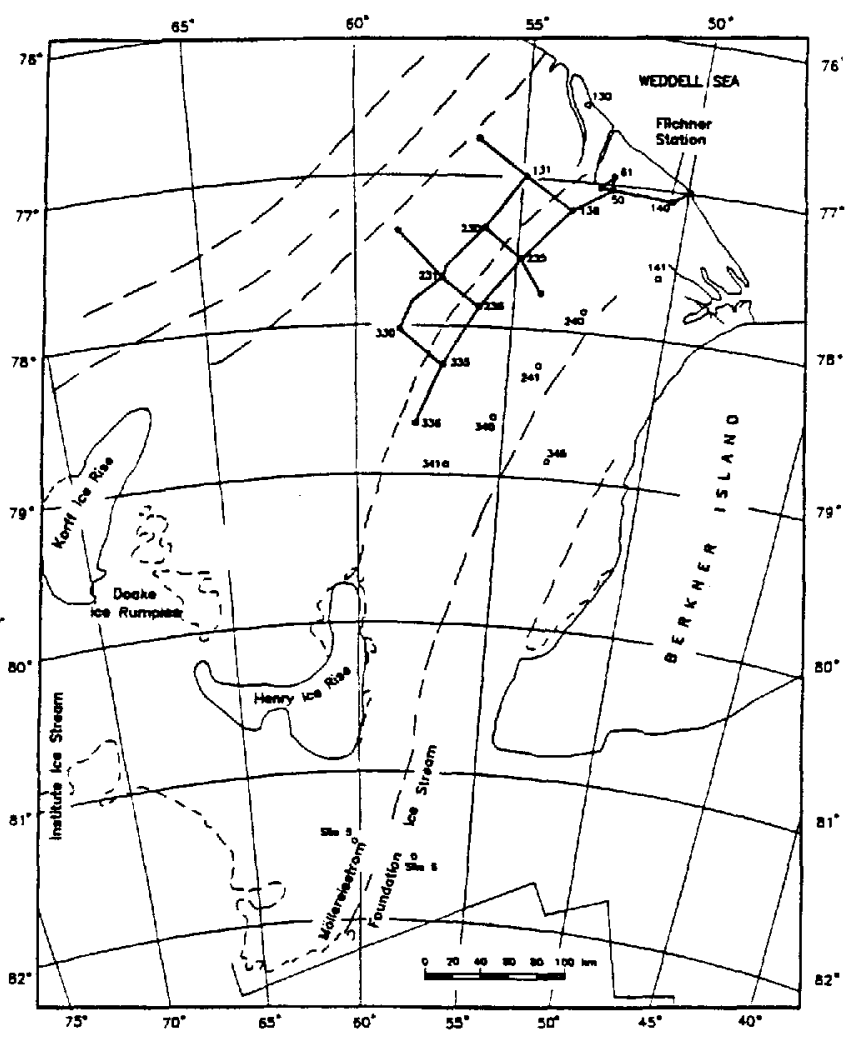

\begin{abstract}
Fig. 1. Location of $40 \mathrm{MHz}$ monopulse RES profiles in the central part of the FRIS. (Map reproduced from Siuthinbank and others, 1988.)
\end{abstract}

\section{INSTRUMENTS AND DATA PROGESSING}

\section{The Münster monopulse RES system}

Our standard system consists of an avalanche-pulse generator, broad-band dipole antennas, a sampling scope and a digital tape recorder. A careful choice of broad-band components has led to sounding depths of more than $1000 \mathrm{~m}$ in normal ice: the 18 stagc avalanche gencrator has a peak amplitude of $2000 \mathrm{~V}$ into $100 \Omega$. It is triggered via a fiber-optic cable. Resistively loaded transmitting and receiving dipole antennas $\mathrm{Wu}_{\mathrm{u}}$ and King, 1965 are used to obtain short pulses; they contribute a loss of $20 \mathrm{~dB}$ compared with simple dipoles. Other broad-band structures with slightly longer pulses lose only $10 \mathrm{~dB}$. Proper matching of the input circuitry avoids ringing and unwanted reflections.

The sampling scope is a modified Tektronix 1503 IDR cable tester with more than $86 \mathrm{~dB}$ dynamic range and a sensitivity of $20 \mu \mathrm{V}$ pp at $100 \mathrm{MHz}$ band width with a sampling frequency of $20 \mathrm{kHz}$. Additional features for time-base calibration, triggering and stacking are providcd. The data are recorded on a Sony digital audio tape (DAT) system offering 16 bit resolution and oversampling. Event marks and spoken commentary are recorded on an extra track.

The accuracy of references in the text and in this list is the responsibility of the author, to whom queries should be addressed.For continuous profiling purposes with constant offset normally $10 \mathrm{~m}$; , the system is triggered by an odometer at adjustable space intcrvals $1-2 \mathrm{~m}$ for measuring from a Skidoo with four tracks per second maximum scan rate. Direct print-out of the constant offset gathers (COG) on an EPG 1600 gray-scale printer scrves as a field record of the profiles. For common midpoint (CMP) measurcments, $450 \mathrm{~m}$ maximum offset is typical on ice shelves with offset increments of 5 or $10 \mathrm{~m}$. For our profiling measurements in the Antarctic and in Greenland, the system is mounted on a Nansen sledge, together with a $500 \mathrm{~W}$ generator, a satcllite-navigation system and communication headsets for operator and Skidoo driver. The antennas are part of light-wcight sleds consisting of fibcrglass rods and metal-free skis lowed behind the Nansen sledgc.

\section{Data processing}

Continuous profiling data and C.MP data are read out digitally from the $\mathrm{DAT}$ recorder on an AT personal computcr. After reduction of oversampling, stacking and resampling to obtain the proper sampling intervals, trigger-time delays are removed. C.MP or COG sections measured with monopulse RES appear almost like seismic sections. They can be treated with a set of programs applying scismic processing techniques, such as band-pass filtcring in the time or frequency domain, amplitude regulation, static and dynamic correction, migration and vclocity analysis. The latter is of special interest for the evaluation of CMP data. Our approach is to use the amplitude-stacking method of Garotta and Michon (1967), which has proved to be a simple and reliable

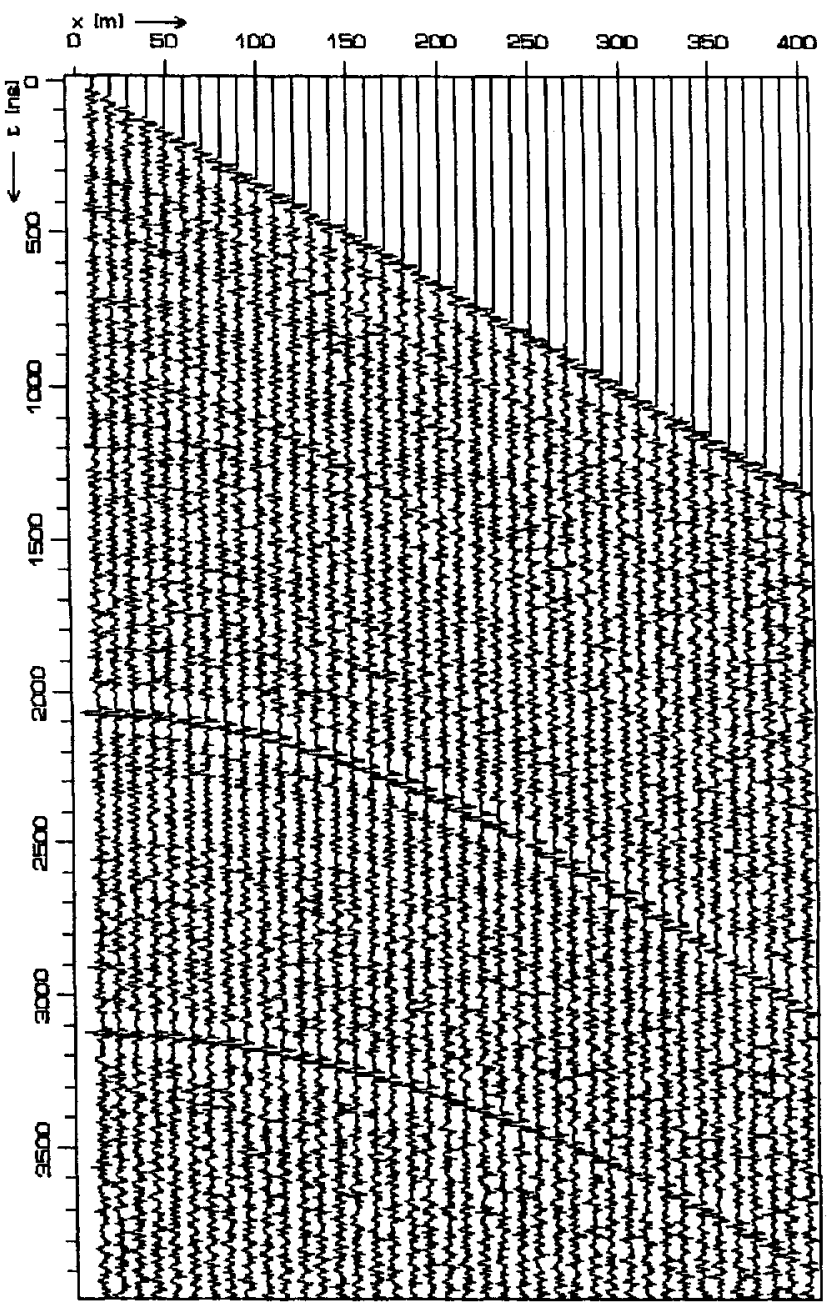

Fig. 2. CMP measured at point 50. MMR at $2.1 \mu \mathrm{s}$, iceshelf bottom at $3.2 \mu$ s zero offset lime. 


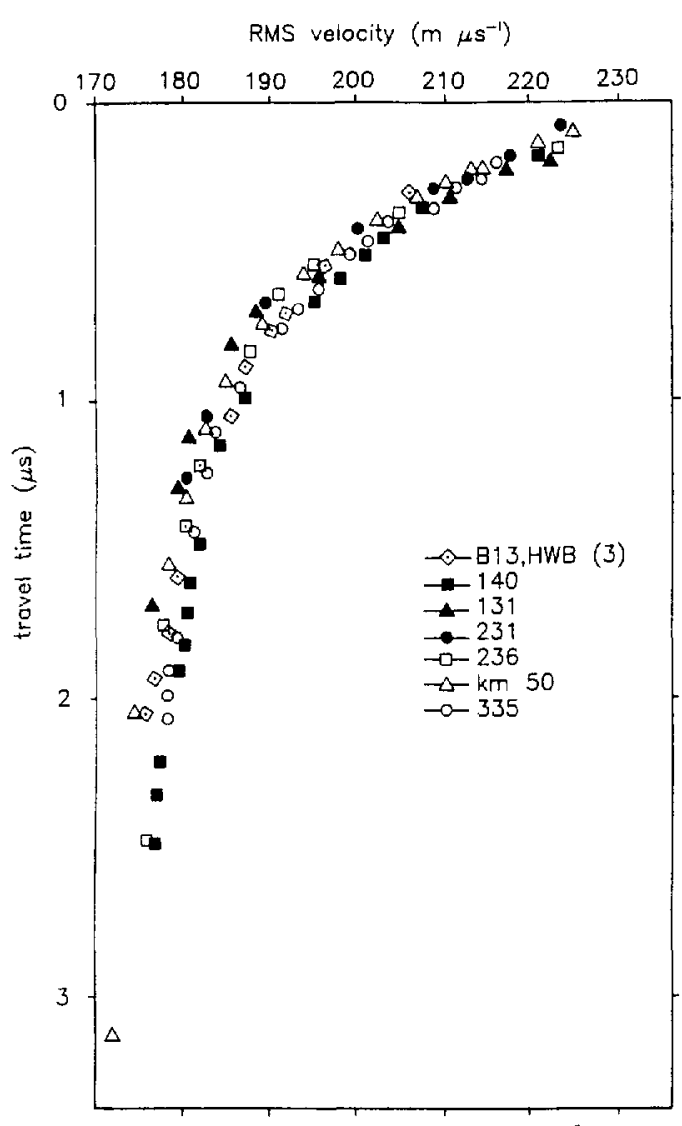

Fig. 3. rms zelocity z's trazel time oblained from velocity analusis of C.MPs measured on the FRIS. tcchnique. The error in velocity determination with CMPs measured on ice shelves has been estimated to about $\pm 1 \mathrm{~m} \mu \mathrm{s}^{-1}$.

\section{GMP MEASUREMENTS}

CMP measurements were made in the vicinity of lilchner Station (point 140), point 61 (three measurements near drill site $B 13$ and the hot-water drillings of 1990 ), point 236 (drill site $\mathbf{B} 15$ ), and points $131,136,231$ and 335 . An example for CMP data is shown in Figure 2. It shows signals of internal layers, the metcoric/marine interfacc reflection (MMR) at $2.1 \mu$ s zero offset time and the iceshelf bottom at $3.2 \mu \mathrm{s}$. The latter reflection is not a common feature for RES in the central part of the FRIS, as pointed out above.

On the whole, nine CMP gathers were obtained in the ccntral part of the Filchncr-Ronne Ice Shelf which only show small variations in the velocity depth function. Velocity vs travel-time plots obtained from the Filchner Ice Shell CMPs are summarized in Figure 3. The in-situ propagation velocity for electromagnetic waves at about $40 \mathrm{MHz}$ in the basal marine-ice layer has been determined as $168 \pm 1 \mathrm{~m} \mathrm{\mu s}^{-1}$, which is the same as in the densified meteoric ice. From the measurcd velocity-travel-time relations, an expression for the calculation of depth $H$ (in $m$ ) from the two-way travel time $t$ (in $\mu$ s) has been derived. They give the proper total thickncss of the ice shelf for the cvaluation of small offset ground-based and airborne soundings. An interval velocity of $168 \mathrm{~m} \mu \mathrm{s}{ }^{1}$ can be used

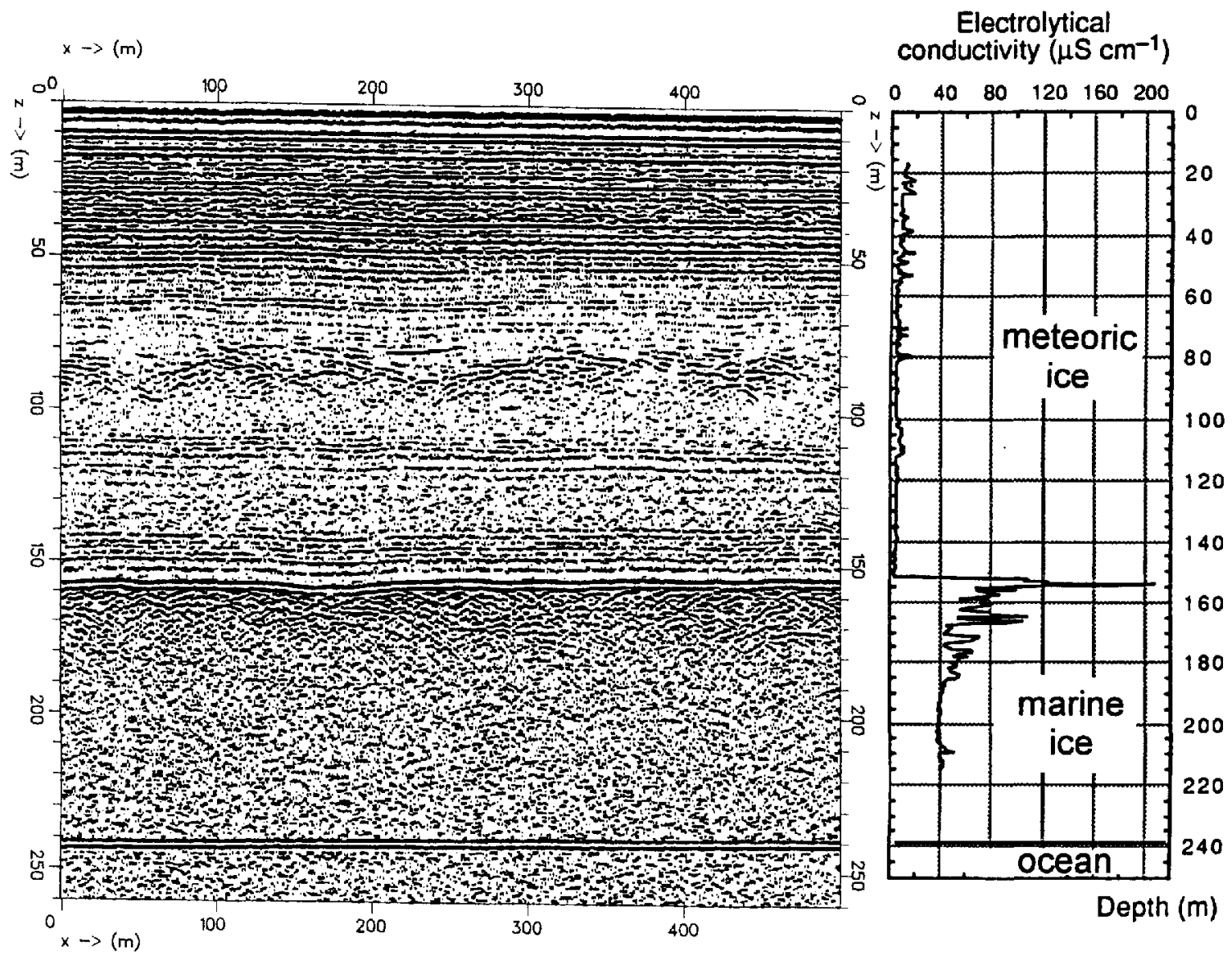

Fig. 4. RES profile nets the core and hol-water drill sile B13. The reflections are corretated with the electrolytical conduclizity profile (modified from Oerter and others (1992a)). MMR at $154 \mathrm{~m}$ depth, bottom reflection al $239 \mathrm{~m}$ depth. 


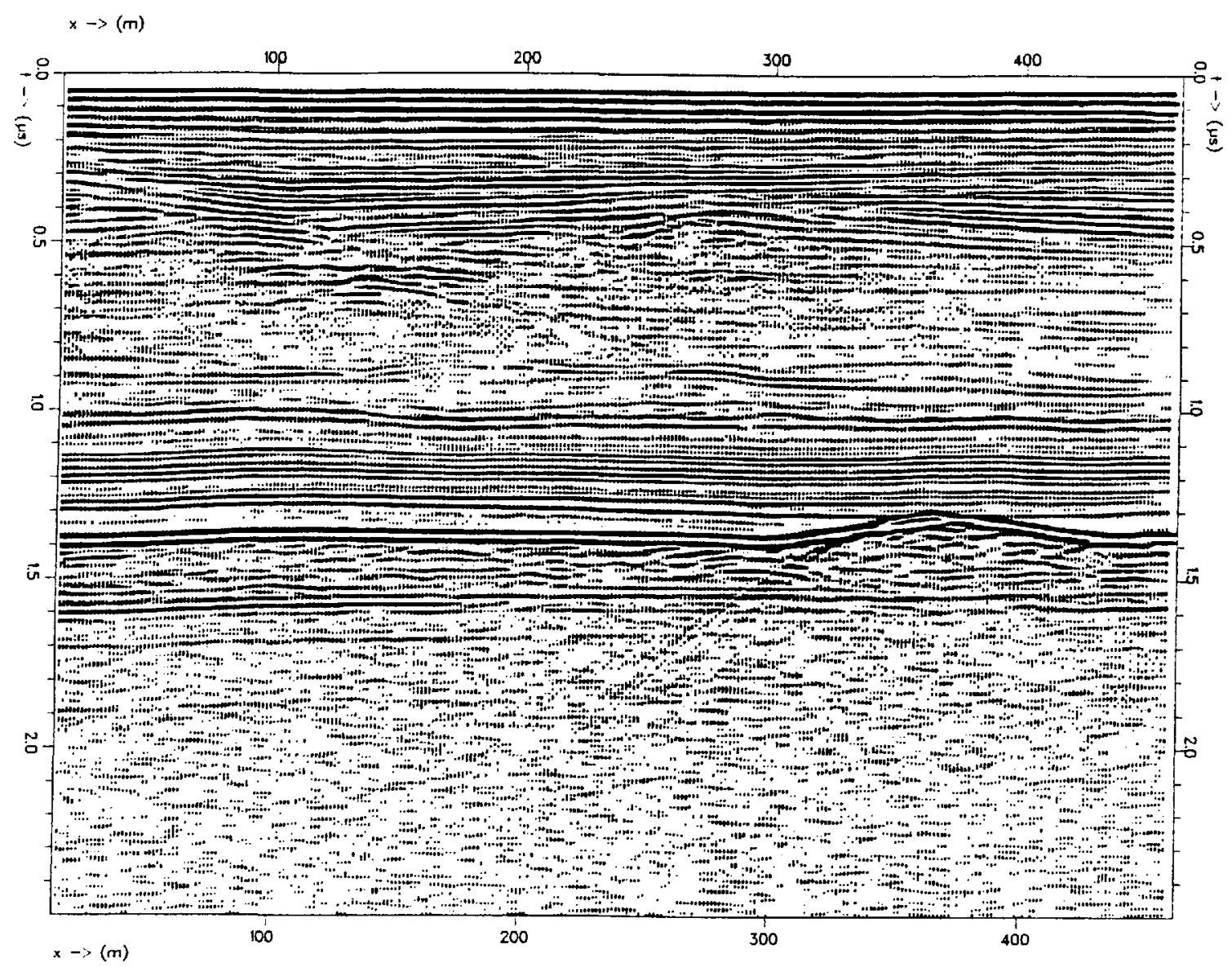

Fig. 5. Processed RES profile near point 330. MMR at 1.4 $\mu$ s, contimuous strata in the marine ice from 1.4 to $1.9 \mu$ s.

with an crror in depth determination of less than $\pm 1 \mathrm{~m}$ below a depth of $100 \mathrm{~m}$. Using the mean values for the nine C.MPs, the following relation for the conversion of travel times into deptlis in the central part of the FRIS holds:

$$
H=8.8+168 \times t / 2(\mathrm{~m})
$$

where $t$ is the two-way travel time in ice given in $\mu$ s and $168 \mathrm{~m} \mu \mathrm{s}$ ' is the propagation velocity in pure ice. The value $8.8 \mathrm{~m}$ is the "stripping correction" which accounts for the air content of the firn. It is at the low end of possible corrections quoted by Bogorodskiy and others 1985), indicating a quick densification process influenced by strain thinning of the ice shelf.

The GMP results at the drill sites give the thickness of the metcoric ice and the marine ice at B13 with a maximum deriation of $0.5 \mathrm{~m}$. The evaluation of CMP-reflection amplitudes will be the subject of a separate paper.

\section{COG MEASUREMENTS (CONTINUOUS PROFILING)}

\section{Structural interpretation}

Figure 4 shows a profile near the core and hot-water drill site B13 with MMR at $153 \mathrm{~m}$ depth and the botom reflection at $239 \mathrm{~m}$ depth. The firn layering, a zone with remnants of crevasses at $80-100 \mathrm{~m}$ depth and deeper layers are visible in the meteoric icc. The reflection coefficient of the meteoric/marine boundary (approx. $-34 \mathrm{~dB}$ ) is wcak compared with an ice/water boundary but distinct in most cases. There is no continuous layering within the marine

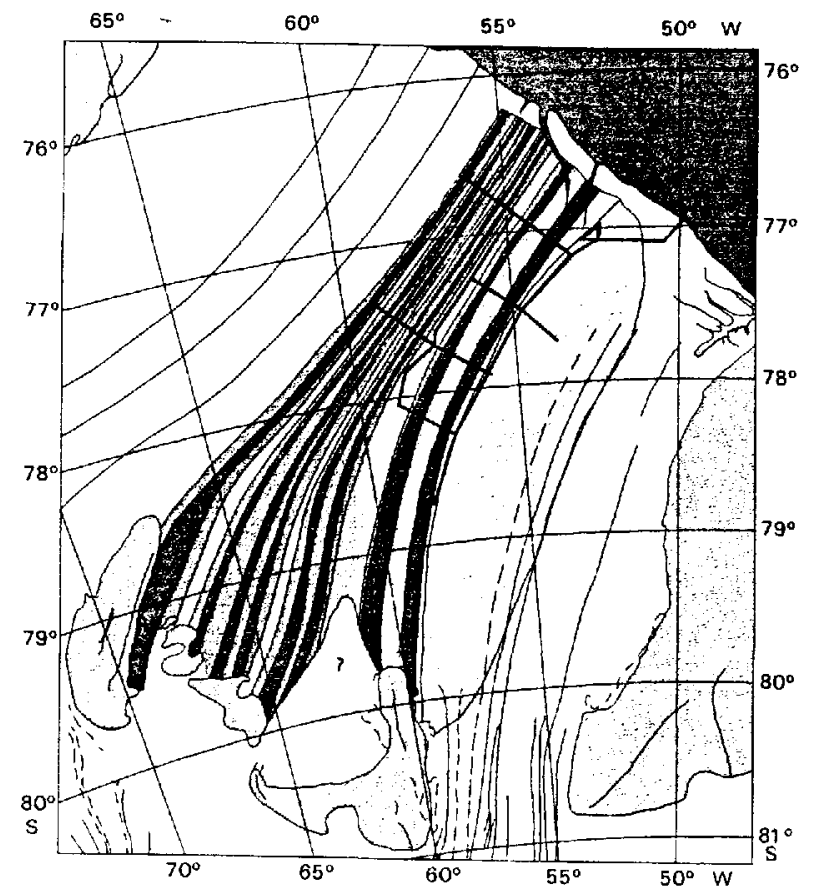

Fig. 6. Pattern of MMR characteristics. Degree of shading denotes degree of distubance, lightest shading meaning an almost smoolh interface. Shading and lines outside the profile grid are extrapolated. 


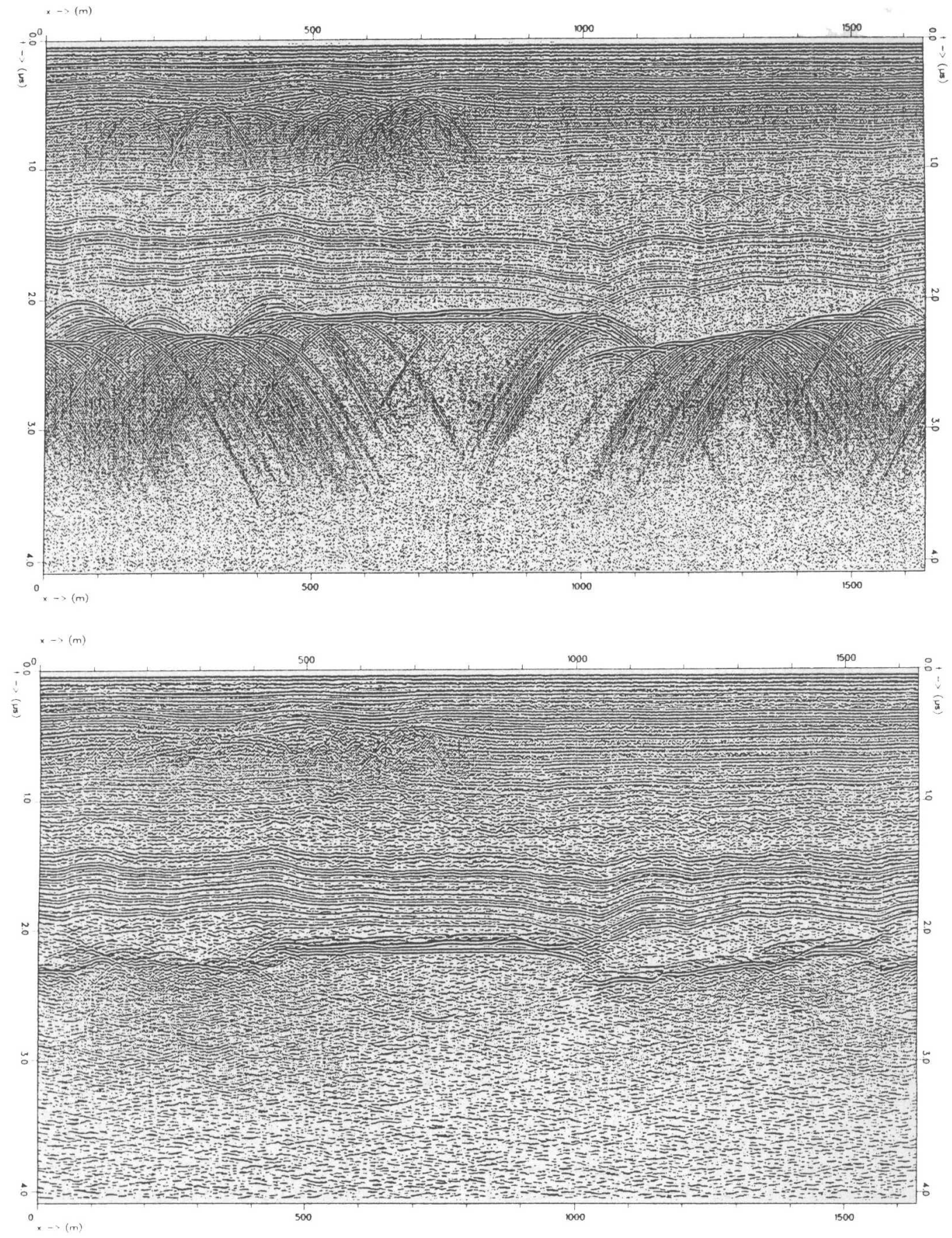

Fig. 7. Part of processed $40 \mathrm{MHz}$ monopulse RES profile downstream of Doake Ice Rumples $\left(77^{\circ} 30^{\prime} S 58^{\circ} 30^{\prime} \mathrm{W}\right)$. Top. Fillering lime-iariable gain. Bollom. Fithering, Firchoff migration, time-variable gain.

ice on this flowline. For comparison, the electrolytical conductivity profile published by Oerter and others (1992a) is shown. Bands of internal layers in the RES profile correlate well with zones of increased conductivity with the most prominent peak and reflection at the top of the marine ice.

Further to the south, the bottom reflection vanishes, partly duc to the relatively high absorption in the marine ice, and partly due to a decrease in reflection coefficient which could be explained by a slushy layer at the bottom (Engellardt and Determarn, 1987). So the MMR is the most significant internal RES horizon in this area of the FRIS and the lowest detectable reflector in most cases.

An exception is the area around a line connecting points 330,235 and 131 . Here, continuous stratification of the marine ice is discernible up to $0.5 \mu$ s two-way travel time below the MMR corresponding to a depth of $42 \mathrm{~m}$ in the marine ice (Fig. 5 ).

In general, the RES results show a variety of internal features related to the flow history (bottom melting, grounding, folding, crevassing, bottom freezing) mainly of the meteoric ice. These features correlate well on parallel profiles perpendicular to the flowlines. 'There is a distinct pattern of undisturbed -slightly disturbed heavily disturbed MMR. 'This pattern can be extrapolated upstream by following flowlines interpreted on satellite images (Swithinbank and others, 1988) which coincide with changes of MMR signatures. It seems obvious that the most disturbed internal reflections originate in the grounding areas at each side of Henry Ice Rise and in 

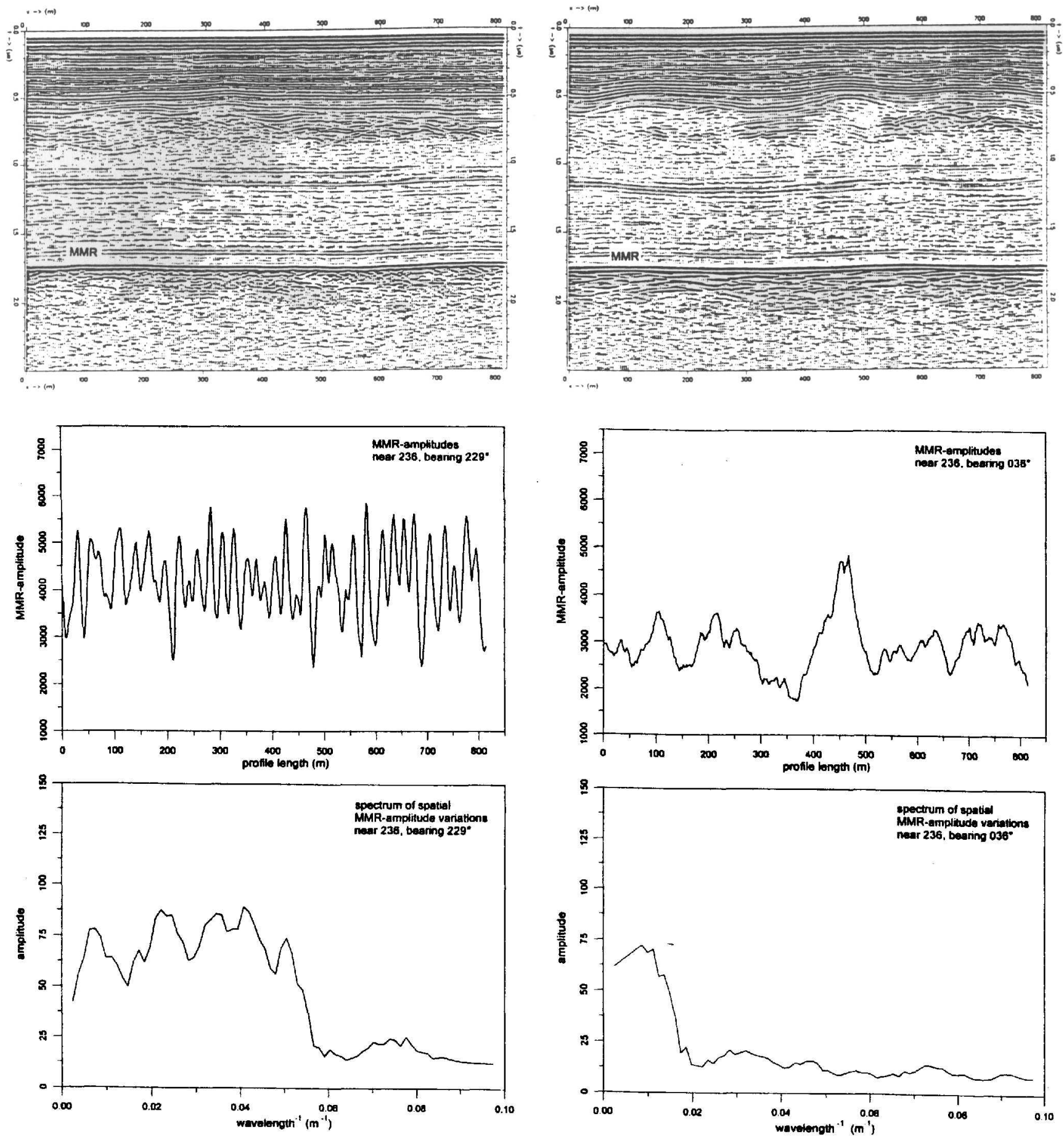

Fig. 8. Variations of MMR amplitudes near point 236 (B15). Flow direction is $033^{\circ}$; left: results almost perpendicular to the flow: night: results almost parallel to the flow. Top: RES profiles showing rather smooth MMR with some diffractions; middle: MMR peak-to-peak amplitudes picked from the profile data (arbitrary units); bottom: spectra of spatinl uniation (amplitudes in abitray units) perpendicular and parallet to the floze direction.

some parts of 1)oake Ice Rumples. The irregular bottom topography of the ice shelf imposed by the movements of grounded parts is preserved from the freezing of a thick marine-ice layer. The appcarance of structures at the previous bottom of the meteoric ice is influenced only by strain effects until they are melted out near the ice edge. 'The distribution of measured and, outside the profile grid, extrapolated MMR features is shown in Figure 6.

The complicated structure of some high-resolution RES sections can be clarified by applying migration techniques which focus diffracted energy to the sources (Fig. 7). The sample profile measured perpendicular to the flow direction displays folding of intermal layers due to lateral compression and step-like features in the deepest reflector (MMR). From the corrclation of such internal structures, flowlines can be constructed.

\section{Amplitudes}

The MMR amplitudes are not constant at constant depths. Even in areas where the reflector is smooth, they can vary by a factor of 2 . Up to now, MMR amplitudes werc investigated in parts of the flowline through the drill-site points $236(\mathrm{~B} 15)$ and 61 (BI3). The results of two 
almost perpendicular profiles in the vicinity of B 15 flow direction: 033; Möller and others, 1992) are compiled in ligure 8. The MMR amplitudes were picked along the COG sections and the spectra of spatial variation (inverse warelength in profilc dircction) were calculated.

Perpendicular to the flow, the spectrum shows strong components between 20 and $50 \mathrm{~m}$ and a slight decay for longer periods. The profile almost parallel to the flow is dominated by long-period components. Variations in MMR ampitudes are most likely due to changes in salinity and/or interface roughness. Salinity changes are indicated by the different electrolytical conductivities observed at the top of the marine ice measurcd on icc cores B 13 with $210 \mu \mathrm{S} \mathrm{cm}{ }^{1}$ and B15 with $310 \mu \mathrm{Scm}{ }^{1}$, while the thicknesses of the high-salinity layers are about the same Oerter and others, $1992 \mathrm{a}, \mathrm{b}$ ).

From the rise lime of the reflections and the trailing signals, no evidence for a roughness of the reflecting horizon less than a wavelength can be inferred. However, the grounding history of the meteoric ice could have caused scratch marks with longer periods at the ice-shelf bottom which could have influenced the freezing. The amplitudes and frequencies of the scratch marks decrease downstrcam towards the drill sites due to strain thinning.

The reason for the observed spatial periods of $20-50 \mathrm{~m}$ remains unexplained. l'rom the experimental set-up using a RLS wavelength in jee of $4 \mathrm{~m}$, the width of the first Fresnel zone for the MMR at B 15 is about $36 \mathrm{~m}$. Hence, the measured amplitude variations are possibly an integral of more small-scale effects.

\section{CONGLUSIONS}

Surface-based measurements with monopulse RES are a powerful tool in the investigation of ice-shelf glaciology, supplcmenting large-scale airborne RES. From the abundance of information about travel times and reflection amplitudes, only a part has been extracted for this paper.

Much interest in the Filchner-Ronne Icc Shelf project las been focused on sub-ice oceanography. Different internal reflection and diffraction signals measured with the monopulse RES show that the basal freezing conditions vary over the ice shelf. The selection of drill sites for occanographic investigations could be supported by a knowledge of the different regimes. Vice versa, reflections related to layers found in core drillings can be traced over large parts of the ice shelf to specify boundary conditions for model calculations.

\section{ACKNOWLEDGEMENTS}

Funding of the work by the (yerman Research Foundation Deutsche lorschungsgemeinschaft and logistic support by the Alfred-Wegener-Institut, Bremerhaven, are gratefully acknowledged. F. Thyssen initiated and focused the work on problems in the area investigated. Thanks are due to him and especially to K. Grosfeld and M. Jonas for many hclpful discussions. Thanks are also due to $\mathrm{W}$. Wilting for his expert electronic engineering, to (chronologically) M. Hoyer, A. Hungeling, K. Grosfeld, L. Hempel, S. Kipfstuhl and N. Rädlcin for thcir help in the field, A. Hungeling and L. Hempel for computer programs used in the evaluation of the RES data, and M. Holthaus and D. Steinhage for their patience in handling gigabytes of data.

\section{REFERENCES}

Blindow, N. 1990. Structures and dielectric properties of meteoric and marine ice in the contral part of the Filchner Ronne Ice Shelf. In Miller, H., d. Filchnor-Ronne-1c'-Shelj-Programme, Report Vo. 4. Bremerhaven, Alfred Wegener Institute, 104108.

Bogorodskiy, V. V., C..R. Bentley and P. F. Gudmandsen. 1985. Ratioglaciologl: Dordrechlt, Reidel.

Engelhardt, $H$. and J. Determann. 1987. Borchole cridence for a thick layer of basal ice in the central Ronne Ice Shelf. Nature, 327(6120), $318-319$

Garotla, R. and D. Michon. 1967. Continuous analysis of velocity function and of the move out correction. Geophsical Prospecting, 15, $.584-597$.

Grosfeld, K. 1993. Investigations on temperature regime and mass balance of the Filchner Ronne Ice Shelf, Antaterica, with special interest regarding molting and freceing processes. Bor. Polargord. 130.

Möller. D., B. Riedel and B. Ritter, 1992. Strain and velocity determination on Ronne Ice Shelf. In Ocrter, H.. ad. Fitcher

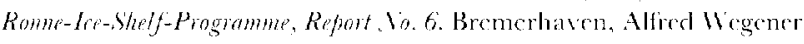
Institute, 61-68.

Oerter. H. and 6 others. 1992a. Evidence for basal marine ice in the Filchner-Ronne Ice Shelf. Natwe, 3586385; 399-401.

Oerter, H., (: Drücker, J. Kipfstuhl, U. Vixdorf and W. Gmaf. 1992h. lhe Filchner IV campaign and the $320 \mathrm{~m}$ deep ice core B15. Ih Oerter, H., ed. Fithne-Ronne-Ice-Shelf-Pongramme, Repont So. 6. Bremerhaven, Alford Wregener Institute, 47-53.

Swithinbank, C., K. Brunk and J. Sievers. 1988. A glaciological map of Filchner-Ronne Ice Shelf, Antaretical. Ann. Glaciol., 11, 150155.

'Thusen, F. 1986. 'The central part of the Filchner Ronnc Ice Slicll. In Kohnen, H., ed. Filcher-Rome-Le-Shelf-Programme. Report Ti. 3. Bremerhaven, Alfred Wegener Institute, 8183.

Thyssen, F. 1988. Special aspects of the central part of Fitchner-Ronne Ice Shelf, Antaretica. Ann. Glaciol., 11, 173-179.

Thyssen, F., A. Bombosch and H. Sandhäger. In press. Elevation, ice thickness and structural maps of the central part of FRIS. Polarforschung.

Wu, T. and R. King. 1965. The cylindrical antenna with nonreflecting resistive loading. IEEE Tiansations on Antennas and Propagation, AP13. $369-373$

The accuracy of references in the text and in this list is the responsibility of the author, to whom queries should be addressed. 